\title{
Report of the Quality Standards Subcommittee of the American Academy of Neurology and the Practice Committee of the Child Neurology Society
}

\author{
S. Ashwal, MD; B.S. Russman, MD; P.A. Blasco, MD; G. Miller, MD; A. Sandler, MD; \\ M. Shevell, MD, CM, FRCP; and R. Stevenson, MD
}

\begin{abstract}
Objective: The Quality Standards Subcommittee of the American Academy of Neurology and the Practice Committee of the Child Neurology Society develop practice parameters as strategies for patient management based on analysis of evidence. For this parameter the authors reviewed available evidence on the assessment of a child suspected of having cerebral palsy (CP), a nonprogressive disorder of posture or movement due to a lesion of the developing brain. Methods: Relevant literature was reviewed, abstracted, and classified. Recommendations were based on a four-tiered scheme of evidence classification. Results: CP is a common problem, occurring in about 2 to 2.5 per 1,000 live births. In order to establish that a brain abnormality exists in children with CP that may, in turn, suggest an etiology and prognosis, neuroimaging is recommended with MRI preferred to CT (Level A). Metabolic and genetic studies should not be routinely obtained in the evaluation of the child with CP (Level B). If the clinical history or findings on neuroimaging do not determine a specific structural abnormality or if there are additional and atypical features in the history or clinical examination, metabolic and genetic testing should be considered (Level C). Detection of a brain malformation in a child with $\mathrm{CP}$ warrants consideration of an underlying genetic or metabolic etiology. Because the incidence of cerebral infarction is high in children with hemiplegic CP, diagnostic testing for coagulation disorders should be considered (Level B). However, there is insufficient evidence at present to be precise as to what studies should be ordered. An EEG is not recommended unless there are features suggestive of epilepsy or a specific epileptic syndrome (Level A). Because children with CP may have associated deficits of mental retardation, ophthalmologic and hearing impairments, speech and language disorders, and oral-motor dysfunction, screening for these conditions should be part of the initial assessment (Level A). Conclusions: Neuroimaging results in children with CP are commonly abnormal and may help determine the etiology. Screening for associated conditions is warranted as part of the initial evaluation.
\end{abstract}

NEUROLOGY 2004;62:851-863

Cerebral palsy $(\mathrm{CP})$ can be defined as a disorder of aberrant control of movement and posture, appearing early in life secondary to a CNS lesion or dysfunction that is not the result of a recognized progressive or degenerative brain disease. ${ }^{1}$ The brain abnormality may occur pre-, peri-, or postnatally. The diagnosis of $\mathrm{CP}$ always involves a motor deficit and the usual presenting complaint for which medical evaluation is sought is that the child is not reaching motor milestones at the appropriate chronological age. In most

Approved by the Quality Standards Subcommittee in March 2003. Approved by the AAN Practice Committee on August 9, 2003. Approved by the AAN Board of Directors on October 18, 2003.

From the Division of Child Neurology (Dr. Ashwal), Department of Pediatrics, Loma Linda University School of Medicine, CA; Departments of Pediatrics and

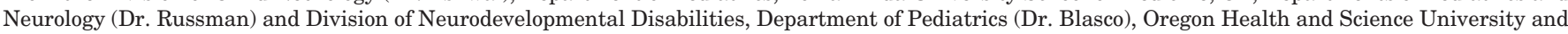
Shriners Hospital for Children, Portland; Pediatrics and Neurology (Dr. Miller), Baylor College of Medicine, Houston, TX; University of North Carolina,

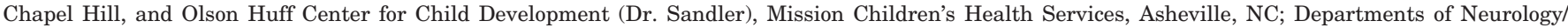

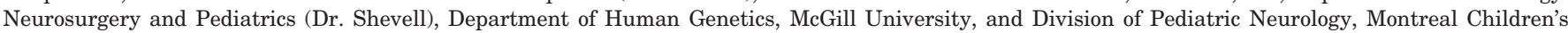
Hospital, Montreal, Quebec, Canada; and Pediatrics (Dr. Stevenson), University of Virginia School of Medicine, Charlottesville.

Received May 27, 2003. Accepted in final form December 24, 2003.

Address correspondence and reprint requests to the Quality Standards Subcommittee of the American Academy of Neurology, 1080 Montreal Avenue, St. Paul, MN 55116. 
instances, a medical history establishes that the child is not losing function, assuring that the patient does not have a progressive disease. This history, combined with a neurologic examination establishing that the patient's motor deficit is due to a cerebral abnormality, leads to the diagnosis of CP. Serial examinations may be necessary to assure the diagnosis of $\mathrm{CP}$, especially when the history is not reliable.

There is agreement that CP is due to a defect or lesion in the developing brain, which may have had its onset in the prenatal, perinatal, or postnatal period. ${ }^{1}$ While often a cutoff age for the appearance of symptoms early in life is generally not given, the great majority of children with $\mathrm{CP}$ present with symptoms as infants or toddlers, and the diagnosis of $\mathrm{CP}$ is made before age 2 years. In some children, symptom onset may be delayed (e.g., dystonic cerebral palsy), whereas in other children the appearance of pseudoprogression of symptoms may occur. The term CP is descriptive and includes a number of etiologies and clinical presentations. Although there is no consensus about a precise age cut-off either for the timing of the insult or the onset of symptoms, of importance is that affected individuals have similar needs for rehabilitation, education, and medical and social services.

$\mathrm{CP}$ is a common problem. The worldwide incidence of CP is approximately 2 to 2.5 per 1,000 live births. ${ }^{2}$ Each year about 10,000 babies born in the United States develop CP. ${ }^{3} \mathrm{CP}$ occurs more commonly in children who are born very prematurely or at term. Data from Sweden on 241 children with CP indicate that $36 \%$ were born at a gestational age (GA) of less than 28 weeks; $25 \%$ at 28 to 32 weeks GA; $2.5 \%$ at 32 to 38 weeks GA; and $37 \%$ at term. ${ }^{2}$

The types and severity of $\mathrm{CP}$ are clinically well established. A Scandinavian study reported that 33\% of the $\mathrm{CP}$ population was hemiplegic, $44 \%$ diplegic, and $6 \%$ quadriplegic. ${ }^{2}$

Half of the individuals with CP use assistive devices such as braces, walkers, or wheelchairs to help develop or maintain mobility and almost $70 \%$ have other disabilities, primarily mental retardation. ${ }^{3}$ Individuals with CP may need specialized medical care, educational and social services, and other help throughout their lives from their families and communities. A study 10 years ago in California of the extra economic costs associated with $\mathrm{CP}$ and 17 other congenital disorders (e.g., Down syndrome, spina bifida) showed that CP had the highest lifetime costs per new case, averaging \$503,000 in 1992 dollars. ${ }^{4}$

Laboratory tests are not necessary to confirm the diagnosis of $\mathrm{CP}$ as it is based on the history and examination. It is a syndrome with many etiologies. Genetic diseases, brain malformations, infections, and anoxic injury to the developing brain are a few of the many causes of CP. Accurate determination of the etiology of $\mathrm{CP}$ has specific implications regarding treatment, prognosis, and ongoing medical management of associated conditions. The importance of de- termining whether there is a malformation, genetic etiology, or injury and whether the injury is due to an acquired pre-, peri-, or postnatal process has obvious significance from the point of view of assessment of recurrence risk, counseling of families, and implementation of prevention programs, and when medicolegal issues arise. Determining causality also helps limit further unnecessary testing. Finally, understanding the etiology of CP has implications for prevention and intervention strategies. This knowledge will direct further research efforts.

Determining the types of evaluations appropriate for children with CP has posed tremendous challenges for parents and health care providers. The purpose of this practice parameter is to review data regarding the value and role of diagnostic tests used to evaluate children diagnosed with CP. Data regarding the role of neuroimaging, metabolic and genetic testing, and evaluation for coagulopathy are discussed. There was insufficient evidence to make any recommendations regarding the role of SPECT scans or evoked potentials in children with CP. This parameter also reviews evidence regarding the prevalence of associated problems such as epilepsy, mental retardation, speech and language disorders, and ophthalmologic and hearing impairments, and the need for their systematic evaluation.

Description of process. Literature searches were conducted with the assistance of the University of Minnesota Biomedical Information Services for relevant articles published from 1980 to March 2002. Medline, CINAHL, and Healthstar databases were searched for relevant articles published from 1966 to 2002, in the English language, using the following key words: CP, magnetic resonance imaging, MRI, computed axial tomography, CT scan, single photon emission tomography, SPECT, metabolic disease, thrombophilia, brain stem evoked potentials, sensory evoked potentials, visual evoked potentials, electroencephalography (EEG), seizures, epilepsy, vision loss, hearing loss, developmental delay, and speech and language delay. Approximately 350 titles and abstracts were reviewed for content regarding the establishment of the etiology of CP. Articles were excluded if the tests were ordered for reasons other than to establish the etiology. We included only studies that contained more than 20 patients; smaller case series were excluded. The ages of infants and children included in these studies were similar to the ages of children typically seen for diagnostic evaluation so it was believed that the evidence-based recommendations included in this parameter were appropriate. It was also believed that as CP is usually due to a static process, it was unlikely for neuroimaging studies to change over time so that data from studies done in older children with CP were valid regarding etiologic yield. Each article was reviewed, abstracted, and classified by a committee member. Data extracted include first author, year, study population, study design, number of patients, types of $\mathrm{CP}$, results of testing, 
Table 1 American Academy of Neurology evidence classification scheme for determining the yield of established diagnostic and screening tests

Class I: A statistical, ${ }^{1}$ population-based ${ }^{2}$ sample of patients studied at a uniform point in time (usually early) during the course of the condition. All patients undergo the intervention of interest. The outcome, if not objective, ${ }^{5}$ is determined in an evaluation that is masked to the patients' clinical presentations.

Class II: A statistical, non-referral-clinic-based ${ }^{3}$ sample of patients studied at a uniform point in time (usually early) during the course of the condition. Most $(>80 \%)$ patients undergo the intervention of interest. The outcome, if not objective,${ }^{5}$ is determined in an evaluation that is masked to the patients' clinical presentations.

Class III: A selected, referral-clinic-based ${ }^{4}$ sample of patients studied during the course of the condition. Some patients undergo the intervention of interest. The outcome, if not objective, ${ }^{5}$ is determined in an evaluation by someone other than the treating physician.

Class IV: Expert opinion, case reports, or any study not meeting criteria for class I to III.

This is a new classification scheme developed by the Quality Standards Subcommittee (QSS) for studies related to determining the yield of established diagnostic and screening tests or interventions and is appropriate only when the diagnostic accuracy of the test or intervention is known to be good. Additionally, the abnormality potentially identified by the screening intervention should be treatable or should have important prognostic implications. This classification is different from others currently recommended by the QSS that have been published in recent parameters that relate to diagnostic, prognostic, or therapeutic studies.

${ }^{1}$ Statistical sample: A complete (consecutive), random, or systematic (e.g., every third patient) sample of the available population with the disease;

${ }^{2}$ Population-based: The available population for the study consists of all patients within a defined geographic region;

${ }^{3}$ Non-referral-clinic-based: The available population for the study consists of all patients presenting to a primary care setting with the condition;

${ }^{4}$ Referral-clinic-based: The available population for the study consists of all patients referred to a tertiary care or specialty setting. These patients may have been selected for more severe or unusual forms of the condition and thus may be less representative;

${ }^{5}$ Objective: An outcome measure that is very unlikely to be affected by an observer's expectations (e.g., determination of death, the presence of a mass on head CT, serum B12 assays).

and outcomes measured. A new four-tiered classification scheme for determining the yield of established diagnostic and screening tests developed by the Quality Standards Subcommittee was utilized as part of this assessment (table 1). This classification scheme is different from the one currently used in recently published practice parameters that evaluate diagnostic, prognostic, or therapeutic articles. Depending on the strength of this evidence, it was decided whether specific recommendations could be made, and if so, the level of strength of these recommendations (table 2).

Neuroimaging. Should neuroimaging be routinely obtained in the child with CP?
Table 2 American Academy of Neurology system for translation of evidence to recommendations

Translation of evidence to

Rating of recommendations recommendations
$\mathrm{A}=$ Established as useful/predictive or not given condition in the specified population

$\mathrm{B}=$ Probably useful/predictive or not useful/predictive for the given condition in the specified population

$\mathrm{C}=$ Possibly useful/predictive or not useful/predictive for the given condition in the specified population

$\mathrm{U}=$ Data inadequate or conflicting. Given current knowledge, test, predictor is unproven. useful/predictive for the
Level A rating requires at least one convincing class I study or at least two consistent, convincing class II studies

Level B rating requires at least one convincing class II study or overwhelming class III evidence

Level $\mathrm{C}$ rating requires at least two convincing class III studies
Evidence. In neonates, neuroimaging is frequently obtained when there is a history of complications during pregnancy, labor, and delivery; when the infant is born very prematurely ( $<32$ weeks); or when neurologic symptoms or findings are present on neonatal examination. A practice parameter regarding the value of and indications for obtaining neuroimaging in preterm and term infants has recently been published. ${ }^{5}$ The current parameter addresses the role of neuroimaging in the infant or child who has been diagnosed with or is suspected of having CP based upon a motor deficit or delay that is not worsening and a history and neurologic examination that places the lesion in the CNS. In some situations, the risks of obtaining a neuroimaging study in an infant with CP may potentially outweigh the benefits of further defining the etiology.

Recent data encompassing a total of 1,426 children who underwent either $\mathrm{CT}^{6-14}$ or $\mathrm{MRI}^{15-24}$ scans indicated an abnormality in $62 \%$ to $100 \%$ of individuals (mean for CT, 77\%; for MRI, 89\%) (tables 3a and 4a). For the combined CT and MRI class I studies $(\mathrm{n}=238), 88 \%$ of children had abnormal scans whereas $77 \%$ of patients in a class II study $(n=22)$ had abnormal scans as did $83 \%$ of children in the class III studies $(\mathrm{n}=1166)$. The timing of the brain insult causing CP may be categorized into prenatal, perinatal, and postnatal subgroups and the neuropathologic changes seen in CP have been linked to the gestational age of the infant at the time of insult. Historical features (e.g., neonatal intracranial hemorrhage, neonatal encephalopathy, stroke, CNS infection, trauma) or prior neuroimaging studies that document such disorders or the presence of a brain malformation may provide sufficient information to establish the etiology when a child is seen later in life as the symptoms of $\mathrm{CP}$ evolve. Likewise, findings 
Table 3 CT in children with cerebral palsy (CP)

a. Overall yield of finding an abnormal CT scan in children with CP

\begin{tabular}{|c|c|c|c|c|c|}
\hline Reference & Class & $\mathrm{N}$ & Ages, y & Type of CP & $\%$ Abnormal \\
\hline Wiklund et al., $1991^{6}$ & I & 83 & $5-16$ & $\mathrm{H}$ & 73 \\
\hline Wiklund et al., $1991^{7}$ & I & 28 & $5-16$ & $\mathrm{H}$ & 75 \\
\hline Miller and Cala, $1989^{8}$ & I & 29 & $6-35$ & $\mathrm{~A}$ & 62 \\
\hline Chen, $1981^{9}$ & III & 281 & $0.08-7$ & M & 84 \\
\hline Kolawole et al., $1989^{10}$ & III & 120 & $1->10$ & M & 73 \\
\hline Taudorf et al., $1984^{11}$ & III & 83 & NA & M & 67 \\
\hline Schouman-Claeys et al., $1989^{12}$ & III & 76 & $0.6-15$ & M & 63 \\
\hline Cohen and Duffner, $1981^{13}$ & III & 52 & $0.67->10$ & $\mathrm{H}$ & 87 \\
\hline Molteni et al., $1987^{14}$ & III & 30 & $5-16$ & $\mathrm{H}$ & 93 \\
\hline Total no. of patients & & 782 & & & \\
\hline Mean abnormal CT & & & & & 77 \\
\hline
\end{tabular}

b. Percent of patients with an abnormal CT scan based on the type of CP ( $\mathrm{n}=485)$

\begin{tabular}{llll}
\hline Hemiplegic $(\mathrm{n}=146)$ & 89 & Quadriplegic $(\mathrm{n}=111)$ & 70 \\
Ataxic $(\mathrm{n}=19)$ & 88 & Hypotonic $(\mathrm{n}=19)$ & 73 \\
Mixed $(\mathrm{n}=29)$ & 79 & Dyskinetic $(\mathrm{n}=14)$ & 36 \\
Diplegic $(\mathrm{n}=153)$ & 75 & & \\
\hline \hline
\end{tabular}

c. Classification of timing of injury of CP based on CT scan abnormalities $(n=626)^{*}$

\begin{tabular}{|c|c|c|c|c|c|c|c|}
\hline Reference & Class & $\mathrm{N}$ & Type of CP & $\%$ Prenatal & $\%$ Perinatal & $\%$ Postnatal & $\%$ Unclassifiable \\
\hline Wiklund et al., $1991^{6}$ & I & 83 & $\mathrm{H}$ & 44 & 39 & 0 & 17 \\
\hline Wiklund et al., $1991^{7}$ & I & 28 & $\mathrm{H}$ & 64 & 82 & 0 & 7 \\
\hline Chen, $1981^{9}$ & III & 282 & M & 33 & 54 & 13 & 0 \\
\hline Kolawole et al., $1989^{10}$ & III & 120 & M & 16 & 35 & 26 & 28 \\
\hline Taudorf et al., $1984^{11}$ & III & 83 & M & 11 & 74 & 15 & 0 \\
\hline Molteni et al., $1987^{14}$ & III & 30 & $\mathrm{H}$ & 53 & 47 & 0 & 0 \\
\hline Total & & 626 & & & & & \\
\hline Mean values & & & & 32 & 50 & 12 & 6 \\
\hline
\end{tabular}

d. Percent of patients with other etiologies of CP based on CT and clinical data $(\mathrm{n}=702)^{*}$

\begin{tabular}{|c|c|c|c|}
\hline Metabolic & 4 & Brain malformation & 7 \\
\hline Genetic & 2 & Treatable condition & 5 \\
\hline
\end{tabular}

* Etiologies could not be determined in all patients in the studies listed in section a and in some patients more than one category of etiology was given. Data from the studies listed in section a.

$\mathrm{H}=$ hemiplegic; $\mathrm{A}=$ ataxic; $\mathrm{M}=$ mixed.

on physical examination (e.g., cataracts, chorioretinitis, dysmorphic features, myoclonus, dystonia) may suggest a specific etiology or an alternative diagnosis. An abnormality on MRI does not necessarily mean that the etiology of the motor deficit has been established. For example, the findings of diffuse cortical atrophy, delayed myelination, or polymicrogyria are nonspecific and only suggest that a CNS disturbance was present and may not allow one to know the underlying cause without a more specific workup.
CT. Data from 782 children with CP who had CT scans found abnormalities in $77 \%$ (range $62 \%$ to $93 \%$ ) (see table $3 a)$. For the class I studies $(\mathrm{n}=140)$, $86 \%$ of children had abnormal scans whereas $78 \%$ of patients in class III studies $(\mathrm{n}=642)$ had abnormal scans (there were no class II studies). The yield from CT scans varied depending on the type of CP (hemiplegic $>$ ataxic $>$ mixed $>$ diplegic $>$ quadriplegic $>$ hypotonic $>$ dyskinetic) with the percent abnormal in those with dyskinetic CP being much lower than in other forms of CP (table $3 \mathrm{~b}$ ). 
Table 4 MRI in children with cerebral palsy $(C P)$

a. Overall yield of finding an abnormal MRI scan in children with $\mathrm{CP}$

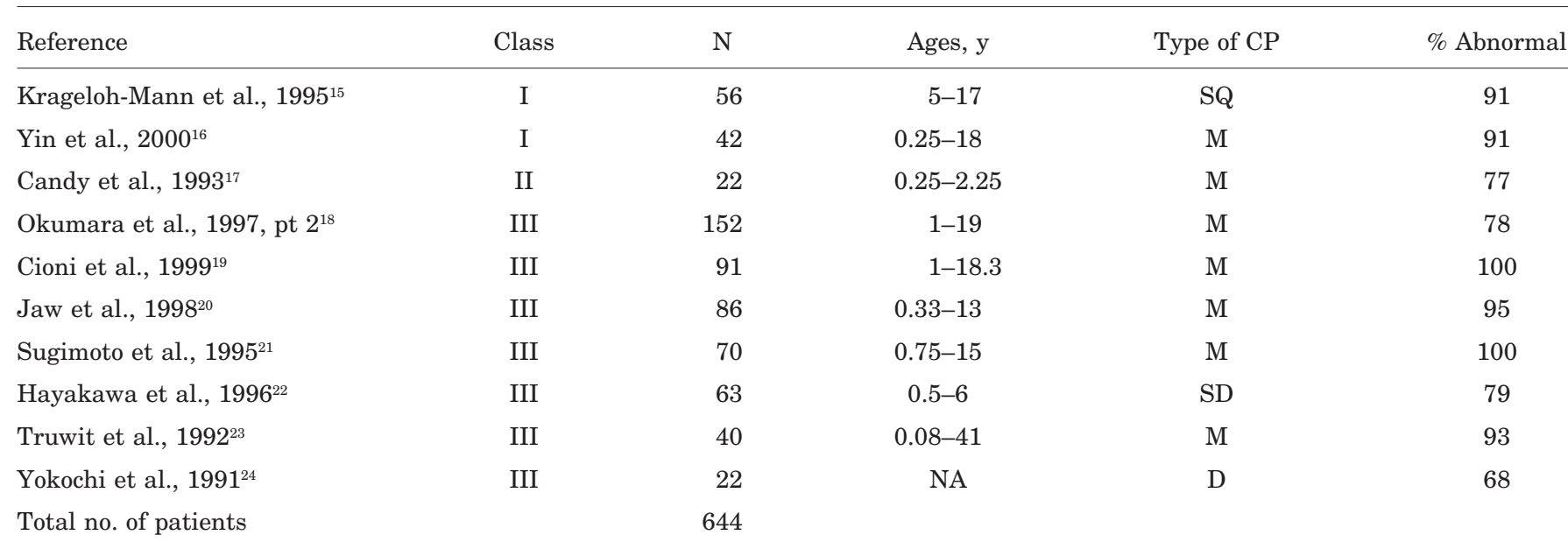

Mean abnormal MRI

89

b. Percent of patients with an abnormal MRI scan based on the type of CP $(n=286)$

\begin{tabular}{|c|c|c|c|c|c|c|c|c|}
\hline Mixed $(\mathrm{n}=4)$ & 100 & & & & & Ataxic $(\mathrm{n}=8)$ & 75 & \\
\hline Quadriplegic $(\mathrm{n}=105)$ & 98 & & & & & Dyskinetic $(\mathrm{n}=10)$ & 70 & \\
\hline Hemiplegic $(\mathrm{n}=50)$ & 96 & & & & & Hypotonic $(\mathrm{n}=6)$ & 67 & \\
\hline Diplegic (n = 102) & 94 & & & & & & & \\
\hline \multicolumn{9}{|c|}{ c. Classification of timing of injury of CP based on MRI scan abnormalities* } \\
\hline \multicolumn{2}{|l|}{ Reference } & Class & $\mathrm{N}$ & Type of CP & $\%$ Prenatal & $\%$ Perinatal & $\%$ Postnatal & $\%$ Unclassifiable \\
\hline \multicolumn{2}{|c|}{ Krageloh-Mann et al., $1995^{15}$} & $\mathrm{I}$ & 56 & $\mathrm{SQ}$ & 14 & 39 & 0 & 46 \\
\hline \multicolumn{2}{|l|}{ Yin et al., $2000^{16}$} & $\mathrm{I}$ & 42 & M & 26 & 54 & 3 & 18 \\
\hline \multicolumn{2}{|l|}{ Cioni et al., $1999^{19}$} & III & 91 & M & 59 & 30 & 11 & 0 \\
\hline \multicolumn{2}{|l|}{ Jaw et al., $1998^{20}$} & III & 86 & M & 29 & 28 & 3 & 8 \\
\hline \multicolumn{2}{|l|}{ Sugimoto et al., $1995^{21}$} & III & 70 & M & 44 & 37 & 0 & 19 \\
\hline \multicolumn{2}{|l|}{ Total } & & 345 & & & & & \\
\hline \multicolumn{2}{|l|}{ Mean values } & & & & 37 & 35 & 4 & 15 \\
\hline
\end{tabular}

d. Percent of patients with other etiologies of CP based on MRI and clinical data $(\mathrm{n}=682)^{*}$

Metabolic 0

Brain malformation 12

Genetic $\quad 1.4$

Treatable condition $\quad 0.1$

* Etiologies could not be determined in all patients in the studies listed in section a and in some patients more than one category of etiology was given. In some studies there were no data provided as to a specific etiology.

$\mathrm{SQ}=$ spastic quadriplegic; $\mathrm{M}=$ mixed; $\mathrm{SD}=$ spastic diplegic $\mathrm{NA}=$ not available; $\mathrm{D}=$ dyskinetic.

When abnormal, CT scans are helpful in delineating the timing of the etiology of CP in most children (table 3c). For the class I studies $(n=111)$, onset was prenatal in $44 \%$, perinatal in $43 \%$, and postnatal in $0 \%$. For the class III studies $(\mathrm{n}=515)$, onset was prenatal in $29 \%$, perinatal in $52 \%$, and postnatal in $15 \%$. In the remaining patients, the timing of the insult was not determined. Some of the more common etiologies of prenatal onset include intrauterine infection, stroke, toxemia, and placental abruption; of perinatal onset, etiologies include hypoxic ische- mic encephalopathy, kernicterus, and trauma; and of postnatal onset, etiologies include infection, trauma, and progressive hydrocephalus. There was insufficient information from the CT studies to calculate an accurate breakdown by specific etiology for any of the three groups although in many of the individual cases a specific etiology was assigned. Etiologies tend to be different in term and preterm babies and are discussed further in the section on MRI.

A CT scan in a child with CP may on occasion detect conditions that are surgically treatable that 
Table 5 MRI abnormalities in children with cerebral palsy based on preterm, term, and postnatal onset of insult

\begin{tabular}{|c|c|c|c|}
\hline Abnormalities & Preterm $(\mathrm{n}=335)$ & Term $(\mathrm{n}=272)$ & Postnatal $(\mathrm{n}=29)$ \\
\hline Acquired lesions & 261 & 178 & 22 \\
\hline PVL with other areas of injury & 227 & 45 & - \\
\hline $\begin{array}{l}\text { Diffuse encephalopathy (cortical/subcortical atrophy/ } \\
\text { ventriculomegaly) }\end{array}$ & 14 & 71 & - \\
\hline Focal ischemic/hemorrhagic (e.g., infarct porencephaly) & 14 & 52 & 10 \\
\hline Multicystic encephalomalacia & 3 & 10 & - \\
\hline Trauma (at birth or later) & 0 & 0 & 4 \\
\hline Infection & 3 & 0 & 8 \\
\hline Malformations* & 48 & 55 & 0 \\
\hline Cortical dysplasia/polymicrogyria & 8 & 18 & - \\
\hline Schizencephaly & 6 & 11 & - \\
\hline Pachygyria/lissencephaly & 5 & 9 & - \\
\hline Complex brain malformation & 22 & 6 & 0 \\
\hline Agenesis/hypoplasia of the corpus callosum & 3 & 3 & - \\
\hline Arachnoid cyst & 1 & 0 & - \\
\hline Vermian/cerebellar hypoplasia & 1 & 2 & - \\
\hline Hydrocephalus/holoprosencephaly/hydranencephaly & 2 & 2 & - \\
\hline Miscellaneous/unknown & 23 & 18 & 1 \\
\hline Miscellaneous etiologies & 22 & 9 & 1 \\
\hline Delayed/abnormal myelination & 1 & 9 & 0 \\
\hline Normal & 3 & 21 & 6 \\
\hline
\end{tabular}

Data from the following studies: Yin et al., 200016; Okumara et al., 1997, pt 218; Cioni et al., 199919; Sugimoto et al., 1995 ${ }^{21}$; Hayakawa et al., 1996 ${ }^{22}$; Krageloh-Mann et al., 1995 ${ }^{15}$; Yokochi et al., 1991 ${ }^{24}$; Candy et al., 1993 ${ }^{17}$; Jaw et al., 1998 ${ }^{20}$; Truwit et al., $1992 .{ }^{23}$ Abnormalities considered insults on neuroimaging were designated as preterm (insult occurred before 38 weeks gestation whether infant born prematurely or at term), term (insult occurred after full term gestation in the perinatal period up to 1 month of age), or postnatal (insult occurred after 1 month of age in infants born prematurely or at term). Malformations were categorized as preterm if detected in infants born before 38 weeks gestation or term if detected in infants born after a full term pregnancy.

* The data in the malformations section of this table are separated into preterm, term, and post-term as that is how they were reported in the original reports. It is believed, however, that these malformations occur prenatally.

PVL = periventricular leukomalacia.

might not be detected by neurologic examination. The chance of finding a surgically treatable lesion based on data from 702 children with various types of CP is $5 \%$ (range $0 \%$ to $22.5 \%$ ) (table $3 \mathrm{~d}$ ). This may vary as one class III study reported that $22.5 \%$ of 120 patients had potentially treatable lesions identified (hydrocephalus, porencephaly, arteriovenous malformation, subdural hematomas and hygromas, and a vermian tumor). ${ }^{10}$ The majority of other studies reported either no patients with potentially treatable lesions ${ }^{6,13,14}$ or lower incidences of $5 \%,{ }^{9} 14 \%,{ }^{11}$ and $17 \% .^{8}$ On occasion, CT (as well as MRI) may detect abnormalities that suggest a potentially treatable inborn error of metabolism.

When the CT scan is abnormal, the presence of coexisting conditions should be anticipated. In studies of 240 children with $\mathrm{CP}$, the presence of mental retardation was greater if scans were abnormal than if they were normal or had minor abnormalities $(78 \%$ versus 39\%)., ${ }^{8,11-13}$ Three of these studies had additional data regarding the relation between CT findings and epilepsy. ${ }^{8,11,12}$ Ninety-one percent of children with CP who had an abnormal CT scan had epilepsy or an abnormal EEG in contrast to only $38 \%$ of children whose scans were normal or minimally abnormal. One of these studies found normal EEG in 37\%, paroxysmal EEG in 44\%, and other abnormalities such as hemispheric asymmetry or suppression of activity in $19 \%$ of children. ${ }^{13}$ Although an abnormal CT suggested greater risk of coexistent conditions, the specific nature of these conditions (e.g., type of epilepsy) did not correlate with scan abnormalities. ${ }^{13}$

Conclusions. Data from three class I (75\%) and six class III (77\%) studies indicate that the yield of finding an abnormal CT scan in a child with CP is high (average of $77 \%$ ) and related to the type of CP. Scan abnormalities may determine an etiology in many children but there were insufficient data to assess this further. Scan abnormalities may occasionally (i.e., 5 to $22 \%$ ) identify treatable conditions and may suggest an increased risk for associated conditions such as mental retardation and epilepsy.

MRI. Data from studies involving 644 children with CP who had MRI scans found abnormalities in 
$89 \%$ (range $68 \%$ to $100 \%$ ) (see table $4 a$ ). For the two class I studies ( $\mathrm{n}=98), 92 \%$ of children had abnormal scans whereas $77 \%$ of patients in one class II study $(\mathrm{n}=22)$ had abnormal scans as did $89 \%$ of children in the class III studies $(\mathrm{n}=524)$. The yield on MRI (table $4 \mathrm{~b}$ ) depended on the type of CP that was present (mixed $>$ quadriplegic $>$ hemiplegic $>$ diplegic $>$ ataxic $>$ dyskinetic $>$ hypotonic) and was somewhat different from that reported using $\mathrm{CT}$.

MRI was helpful in determining whether the injury was prenatal, perinatal, or postnatal in onset (table 4c). Based on studies involving 345 children (class I $\mathrm{n}=98$; class III $\mathrm{n}=247$ ) with different types of CP, onset was prenatal in $37 \%$ (29\% in class I and $45 \%$ in class III studies), perinatal in $35 \%$ (45\% in class I and $31 \%$ in class III), and postnatal in $4 \%$ (1\% in class I and $5 \%$ in class III studies). The yield from MRI also depended on whether the child with CP was born prematurely, at term, or whether CP was due to an insult later in life. Data from studies on 620 patients found that MRI scans were abnormal in 332/335 (99\%) preterm infants, 251/272 (92\%) term infants, and 23/29 (79\%) infants older than 1 month (table 5). In most series, this was due to the fact that MRI was more sensitive in detecting periventricular leukomalacia, other perinatally acquired lesions, as well as subtle congenital anomalies of brain development. MRI can help define abnormalities based on the timing of insult in most patients as summarized in table 5. The etiology of CP in these children was suggested or established based on neuroimaging findings in combination with the clinical history.

Conclusions. Data from two class I (92\%), one class II (77\%), and seven class III studies (89\%) indicate that the yield of finding an abnormal MRI scan in a child with CP is very high (average of $89 \%$ ) and greater than that reported using CT (77\%). The yield on MRI (as with CT) depends on the type of CP that is present. MRI is more likely to be abnormal in cases of CP associated with prematurity, showing abnormalities such as periventricular leukomalacia, compared to infants born at term. An etiology of CP can be determined in many patients based on the results of neuroimaging in combination with the clinical history.

Recommendations. 1. Neuroimaging is recommended in the evaluation of a child with $\mathrm{CP}$ if the etiology has not been established; for example, by perinatal imaging (Level A, class I and II evidence).

2. MRI, when available, is preferred to CT scanning because of the higher yield of suggesting an etiology and timing of insult leading to CP (Level A, class I-III evidence).

Metabolic and genetic testing. Should metabolic or genetic testing be routinely ordered in children with CP?

Evidence. Data from 2 class I, 13 class II, and 4 class III studies on 1,384 children with $\mathrm{CP}$ who underwent neuroimaging (CT or MRI) and who also had metabolic and genetic testing indicate that it is rare to identify an underlying metabolic or genetic disorder. The mean incidence of metabolic (4\%) and genetic disorders $(2 \%)$ in those children who had CT scans was slightly higher than with MRI (metabolic, $0 \%$; genetic, $1.4 \%$ ) and did not vary substantially between the different classes of studies (see tables $3 \mathrm{~d}$ and $4 \mathrm{~d}$ ). The low and variable incidence of metabolic and genetic disorders in these studies was, in part, due to patient selection factors, as in some studies children with metabolic disorders were excluded from analysis. ${ }^{17}$ Also, in these retrospective studies, the extent and type of metabolic or genetic testing was variable so that the exact prevalence of such disorders in children with CP remains uncertain.

Since the advent of neuroimaging, it has become more apparent that children with CP may have congenital brain malformations. Data from this same group of 1,426 children found that $7 \%$ of patients who had a CT scan and $12 \%$ of those who underwent MRI had major brain malformations such as lissencephaly, schizencephaly, or pachygyria (see tables $3 \mathrm{~d}$ and $4 \mathrm{~d}$ ). Because these malformations are ever increasingly associated with specific genetic disorders (e.g., lissencephaly/Miller-Dieker syndrome/chromosome $17 \mathrm{p} 13.3$ ), their presence in affected children indicates the need for further genetic testing. Certain neurometabolic disorders (e.g., peroxisomal disorders such as Zellweger syndrome) may be associated with cerebral malformations and can present within the first years of life with a motor deficit that might appear to be nonprogressive. At present, no studies have prospectively evaluated children with CP with or without brain malformations to determine the incidence of metabolic or genetic abnormalities.

Metabolic disorders may on rare occasions masquerade as CP. Six small case series (i.e., class IV studies) describe 30 children who ultimately developed what appeared to be dyskinetic CP due to glutaric aciduria (type 1). ${ }^{25-30}$ These children typically develop normally until 5 to 10 months of age when they suffer an acute encephalopathy manifested by coma that is followed by dystonia, motor impairment, and macrocephaly (in about 60\%). ${ }^{25}$ Distinctive MRI and CT findings occur in half the patients and are manifested by frontal and temporal atrophy. Early diagnosis is important as glutaric aciduria is treatable; early intervention may prevent significant motor and cognitive impairment. ${ }^{28}$ Other metabolic disorders presenting with symptoms suggestive of $\mathrm{CP}$ also have been reported in small case series and include LeschNyhan syndrome, ${ }^{31} 3$-methylglutaconic aciduria, ${ }^{32}$ pyruvate dehydrogenase deficiency, ${ }^{33}$ argininemia, ${ }^{34}$ cytochrome oxidase deficiency, ${ }^{35}$ succinic semialdehyde dehydrogenase deficiency, ${ }^{36}$ and female carriers of ornithine transcarbamylase deficiency ${ }^{37}$

Other childhood neurologic disorders (e.g., doparesponsive dystonia, hereditary spastic paraplegia, ataxia telangiectasia) may initially be misdiagnosed as CP because of the slow rate of progression of symptoms. Other clinical or laboratory features of 
Table 6 Associated conditions in children with cerebral palsy

\begin{tabular}{|c|c|c|c|c|c|c|}
\hline Reference & Class & $\mathrm{N}$ & $\begin{array}{l}\% \text { Mental } \\
\text { retardation }\end{array}$ & $\begin{array}{c}\% \text { Visual } \\
\text { defects }\end{array}$ & $\begin{array}{c}\% \text { Speech-language } \\
\text { disorders }\end{array}$ & $\begin{array}{c}\% \text { Hearing } \\
\text { impaired }\end{array}$ \\
\hline Zafeiriou et al., $1999^{47}$ & I & 493 & 40 & 39 & 54 & 15 \\
\hline von Wendt et al., $1985^{49}$ & I & 69 & 70 & 19 & NA & 7 \\
\hline Kolawole et al., $1989^{10}$ & III & 120 & 66 & 15 & 59 & 14 \\
\hline
\end{tabular}

$\mathrm{NA}=$ not available.

such conditions and observations over time that neurologic symptoms are progressive should suggest that the child does not have $\mathrm{CP}$ and mandates the need for further evaluation.

Conclusions. Metabolic or genetic causes for CP occur infrequently (i.e., 0 to $4 \%$ ). However, the true incidence is unknown as there have been no prospective studies that have examined this issue. In almost all such cases, there are atypical complaints, features in the history of a progressive rather than a static encephalopathy, findings on neuroimaging that are representative of certain genetic or metabolic disorders, or a family history of childhood neurologic disorder with associated CP. Neuroimaging studies have shown that 7 to $11 \%$ of children with $\mathrm{CP}$ will have a brain malformation suggesting additional risk for genetic and possibly a metabolic etiology.

Recommendations. 1. Metabolic and genetic studies should not be routinely obtained in the evaluation of the child with CP (Level B, class II and III evidence).

2. If the clinical history or findings on neuroimaging do not determine a specific structural abnormality or if there are additional and atypical features in the history or clinical examination, metabolic and genetic testing should be considered (Level C, class III and IV).

3. Detection of a brain malformation in a child with CP warrants consideration of an underlying genetic or metabolic etiology (Level C, class III and IV evidence).

Coagulopathies. Should coagulation studies be performed in children with CP?

Evidence. Patients with hemiplegic $\mathrm{CP}$ frequently have suffered a prenatal or perinatal cerebral infarction. Data from three CT studies listed in table $3 \mathrm{a}(\mathrm{n}=196)$ found cerebrovascular occlusion, usually in the middle cerebral artery distribution, in $13 \%,{ }^{6} 32 \%,{ }^{11}$ and $37 \%{ }^{14}$ of individuals. There are insufficient data concerning the incidence of cerebral infarction or other causes of cerebrovascular compromise in children with other forms of CP.

Children, in contrast to adults, often have a coagulopathy, congenital heart disease, or an infectious process as the etiology of stroke. ${ }^{38}$ However, none of the MRI series listed in table 4a focused on children with hemiplegic CP. None of the reported series (see tables 3 and 4) included information indicating that a systematic examination for the etiology of infarction was performed. One class I study ${ }^{39}$ and several class II studies have reported coagulation abnormalities as the etiology of neonatal cerebral infarction. ${ }^{39-42}$ These have included Factor V Leiden deficiency, the presence of anticardiolipin or antiphospholipid antibodies, and Protein C or S deficiency. One class III study ${ }^{42}$ and several class IV case reports ${ }^{43-46}$ have also described the relation between neonatal cerebral infarction, coagulopathies, and a later diagnosis of hemiplegic CP.

Conclusions. Class I-III evidence indicates that cerebral infarction due to pre- or perinatal cerebrovascular occlusion occurs in 13 to $37 \%$ of children with hemiplegic CP. Class II and III evidence suggests that an etiology of cerebral infarction in this population may be due to a coagulation disorder and that the yield of testing will be higher if done in the neonatal period rather than if the child is evaluated later at the time of diagnosis of CP. There is insufficient evidence regarding the relation between coagulation disorders and other forms of CP.

Recommendations. Because the incidence of unexplained cerebral infarction seen with neuroimaging is high in children with hemiplegic CP, diagnostic testing for a coagulation disorder should be considered (Level B, class II-III evidence). There is insufficient evidence to be precise as to what studies should be ordered.

Associated conditions. What evaluations for associated conditions should be performed in children with CP?

Evidence. Children with $\mathrm{CP}$ often have associated conditions such as mental retardation or epilepsy that are equal in severity to their motor impairment. Because of the motor difficulties associated with $\mathrm{CP}$, these conditions may not be readily recognized. These conditions may also seriously hamper the ability of a child to realize his or her intrinsic developmental potential.

Data from three class I and one class II studies involving 886 children with CP summarize the frequency of some of the major associated conditions that occur in children with CP (table 6). ${ }^{47-49}$ The incidence of mental retardation (52\%), epilepsy (45\%), ophthalmo- 
Table 7 Prevalence of epilepsy in children with cerebral palsy

\begin{tabular}{|c|c|c|c|c|}
\hline Reference & Class & $\mathrm{N}$ & Types of cerebral palsy & $\%$ Patients with epilepsy \\
\hline Murphy et al., $1993^{48}$ & I & 204 & M & 46 \\
\hline von Wendt et al., $1985^{49}$ & I & 69 & M & 48 \\
\hline Miller and Cala, $1989^{8}$ & I & 29 & $\mathrm{~A}$ & 59 \\
\hline Zafeiriou et al., $1999^{50}$ & II & 493 & M & 36 \\
\hline Hadjipanayis et al., $1997^{51}$ & II & 323 & M & 42 \\
\hline Al-Sulaiman, $2001^{52}$ & II & 151 & M & 54 \\
\hline Chambers et al., $1999^{53}$ & II & 114 & M & 36 \\
\hline Bruck et al., $2001^{54}$ & II & 100 & M & 62 \\
\hline Cioni et al., $1999^{19}$ & II & 91 & M & 35 \\
\hline Kwong et al., $1998^{55}$ & II & 85 & M & 38 \\
\hline Kaushik et al., $1997^{56}$ & II & 50 & M & 56 \\
\hline Taudorf et al., $1984^{11}$ & III & 83 & M & 35 \\
\hline Senbil et al., $2002^{57}$ & III & 74 & M & 42 \\
\hline Cohen and Duffner, $1981^{13}$ & III & 52 & $\mathrm{H}$ & 58 \\
\hline Total & & 1918 & & 43 \\
\hline
\end{tabular}

$\mathrm{M}=$ mixed; $\mathrm{A}=$ ataxic $\mathrm{H}=$ hemiplegic.

logic defects (28\%), speech and language disorders (38\%), and hearing impairment (12\%) are quite significant. Data from some of these studies also suggest that those children who have abnormal neuroimaging are more likely to have one or more of these deficits and in some of the studies severity of scan findings was associated with the severity of deficit.

Epilepsy. Should EEG be routinely performed in the assessment of children with CP?

Evidence. Given the higher frequency of epilepsy in children with CP, EEG is often considered during the initial evaluation. ${ }^{47}$ The utility of EEG from a diagnostic perspective in this population has not been prospectively investigated. The vast majority of articles on EEG and CP are class III and IV studies that describe the frequency and types of seizures in children with different forms of CP but do not address the role of EEG in determining the etiology of $\mathrm{CP}$ nor in predicting the development of seizures in a child with CP.

Data from studies involving 1,918 children have found on average that $43 \%$ (range 35 to $62 \%$ ) of children with CP develop epilepsy (table 7). In the three class I studies $(\mathrm{n}=302), 48 \%$ had epilepsy in contrast to $42 \%$ of the children in the eight class II studies $(\mathrm{n}=1,407)$ and $43 \%$ in the class III studies $(\mathrm{n}=209)$. In none of these studies was there evidence that the EEG was useful in determining the etiology of the child's CP.

Data from one class II study compared patients with CP and epilepsy to those with epilepsy alone..$^{55}$ Children with CP had a higher incidence of epilepsy with onset within the first year of age (47\% versus $10 \%)$, history of neonatal seizures (19\% versus $3 \%$ ), status epilepticus (16\% versus $1.7 \%$ ), need for polytherapy (25\% versus $3 \%$ ), and treatment with second-line antiepileptic drugs (31\% versus $6.7 \%$ ).
They also had a lower incidence of generalized seizures (28\% versus $59 \%)$ and of remaining seizure free $(37 \%$ versus $90 \%){ }^{55}$ Factors associated with a seizure-free period of 1 year or more in epileptic children with CP include normal intelligence, single seizure type, monotherapy, and spastic diplegia. Similar findings have been observed by other investigators in the studies listed in table 7 and are summarized in the review by Wallace. ${ }^{47}$ Children with $\mathrm{CP}$ who have abnormal neuroimaging studies are more likely to have epilepsy. One class I and two class II CT studies have examined the association between CT findings and epilepsy.8,11,13 Fifty-four percent of children with $\mathrm{CP}$ and an abnormal CT had epilepsy in contrast to only $27 \%$ of those who had a normal scan. In one study, EEG abnormalities (described as paroxysmal or asymmetric) were also much more commonly found in those children with an abnormal CT scan. ${ }^{13}$

The prevalence of epilepsy also varies depending on the type of $\mathrm{CP}$ that is present. Data from the studies listed in table 7 indicate that children with spastic quadriplegia (50 to 94\%) or hemiplegia (30\%) have a higher incidence of epilepsy than patients with diplegia or ataxic CP (16 to $27 \%$ ). In patients with dyskinetic $\mathrm{CP}$, it may occasionally be difficult to differentiate partial complex seizures from dyskinetic movements.

Conclusions. Although approximately $45 \%$ of children with CP develop epilepsy, in none of the retrospective studies involving 2,014 children was there evidence that the EEG was useful in determining the etiology of the child's CP. There is no evidence to make any recommendation regarding the child with $\mathrm{CP}$ who does not have a history of seizures as to whether an EEG should be ordered to screen for epileptiform abnormalities. 
Recommendations. 1. An EEG should not be obtained for the purpose of determining the etiology of CP (Level A; class I and II evidence).

2. An EEG should be obtained when a child with $\mathrm{CP}$ has a history or examination features suggesting the presence of epilepsy or an epileptic syndrome (Level A; class I and II evidence).

Mental retardation. Cognitive and neuropsychological function in children with $\mathrm{CP}$ are commonly impaired..$^{58}$ In general, there is some but no absolute relation between the type of $\mathrm{CP}$ and severity of cognitive impairment. Children with spastic quadriplegia have greater degrees of mental impairment than children with spastic hemiplegia. Motor deficits of children with spastic CP appear to correlate with the severity of cognitive deficits in contrast to those children with dyskinetic CP where this relation is lacking. 58

Children with different forms of CP may be difficult to assess because of the motor deficits and in some forms of CP (e.g., spastic diplegia) the differences between performance and verbal intelligence test scores actually increase with age.$^{59}$ Laterality of hemiplegia may also be a contributing factor-those children with right hemiplegia may be more likely to have impaired language function due to left hemisphere injury, ${ }^{59}$ although this remains controversial. ${ }^{60}$ There is also a strong association between greater intellectual impairment in children with $\mathrm{CP}$ and the presence of epilepsy, an abnormal EEG, or an abnormal neuroimaging study. ${ }^{47}$

Ophthalmologic impairments. Visual impairments and disorders of ocular motility are common (28\%) in children with CP (see table 6). There is an increased presence of strabismus, amblyopia, nystagmus, optic atrophy, and refractive errors ${ }^{61}$ Children whose CP is due to periventricular leukomalacia are also more likely to have visual perceptual problems. Many of these difficulties should be detected if currently accepted guidelines for vision screening in children with CP are employed. ${ }^{62,63}$

Speech and language disorders. Because of bilateral corticobulbar dysfunction in many CP syndromes, anarthric or dysarthric speech and other impairments related to oral-motor dysfunction are common. For example, articulation disorders and impaired speech intelligibility are present in $38 \%$ of children with CP (see table 6). ${ }^{64,65}$ Because their impaired mobility can cause limited interaction with individuals in the environment, children with $\mathrm{CP}$ might not be able to develop the linguistic skills necessary to develop more complex speech patterns. ${ }^{66}$ Language (as opposed to speech) deficits in CP go hand in hand with verbal intellectual limitations associated with mental retardation. ${ }^{67}$ Oral-motor problems including feeding difficulties, ${ }^{68-70}$ swallowing dysfunction, ${ }^{65,70}$ and drooling ${ }^{71}$ may lead to potential serious impacts on nutrition and growth, ${ }^{72}$ oral health, ${ }^{73,74}$ respiration, ${ }^{75}$ and self-esteem.

Hearing impairment. Hearing impairment occurs in approximately $12 \%$ of children with $\mathrm{CP}$ (see table 6).
This occurs more commonly if the etiology of CP is related to very low birth weight, kernicterus, neonatal meningitis, or severe hypoxic-ischemic insults. Children with $\mathrm{CP}$ who have mental retardation or abnormal neuroimaging studies are at greater risk for hearing impairment. Of concern are recent studies from the Centers for Disease Control that almost half the children found to have severe congenital hearing loss (with or without CP) in the greater Atlanta area were not recognized until almost age 3 years. ${ }^{76}$ Established guidelines for neonatal audiometric screening have recently been published. ${ }^{77}$

Conclusions. Children with CP are more likely to have associated conditions including mental retardation (52\%), ophthalmologic defects (28\%), hearing impairment $(12 \%)$, and speech and language disorders (38\%) and additional oral-motor deficits. Children with $\mathrm{CP}$ are also at greater risk for epilepsy (mean 43\%; range 34 to $94 \%$ ). However, there is no evidence that an EEG is helpful in determining the etiology of CP.

Recommendations. Because of the high incidence of associated conditions, children with $\mathrm{CP}$ should be screened for mental retardation, ophthalmologic and hearing impairments, and speech and language disorders (Level A, class I and II evidence). Nutrition, growth, and other aspects of swallowing dysfunction should be monitored. Further specific evaluations are warranted if screening suggests areas of impairment.

Recommendations for the evaluation of children with CP. Although there is insufficient evidence to recommend the optimal sequence of tests to determine the etiology of $\mathrm{CP}$, taking into account diagnostic yield and potential treatability, we propose the following consensus-based evaluation as outlined in the algorithm (figure). All children should undergo a detailed history and physical examination. It is important to determine that the child's condition is due to a static and not a progressive or degenerative neurologic disorder. It is also important to classify the type of CP as this has diagnostic implications as well as implications regarding associated problems. Because children with CP commonly have associated mental retardation, ophthalmologic abnormalities, hearing impairments, speech and language disorders, and disorders of oral-motor function, screening for these conditions should be part of the initial assessment. An EEG is recommended when there are features suggestive of epilepsy or a specific epileptic syndrome. In order to establish an etiology and prognosis in children with $\mathrm{CP}$, neuroimaging is recommended, with MRI preferred to CT. However, if neuroimaging performed in the perinatal period provided an etiology of the child's CP, it may obviate the need for later study. Metabolic and genetic studies should not be routinely obtained in the evaluation of the child with CP. If the clinical history or findings on neuroimaging do not determine a specific structural abnormality or if there are additional and atypical features in 
History and Examination Findings Suggest Diagnosis of CP (non-progressive disorder of motor control)
1. Confirm that the history does not suggest a progressive or degenerative central nervous system disorder.

2. Assure that features suggestive of progressive or degenerative disease are not present on examination.

3. Classify the type of CP (quadriplegia, hemiplegia, diplegia, ataxic, etc). For the most part this classification system is one of convenience, i.e., easy communication. It does not necessarily relate to prognosis or to what treatments are indicated.

4. Screen for associated conditions including:

a. Developmental delay/mental retardation

b. Ophthalmologic/hearing impairments

c. Speech and language delay

d. Feeding/swallowing dysfunction

e. If history of suspected seizures, obtain an EEG

Did the child have previous neuroimaging or other laboratory studies? (e.g., in neonatal period) that determined the etiology of CP?

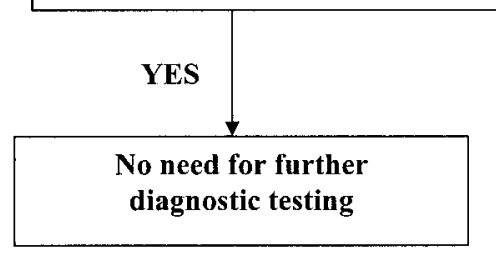

NO

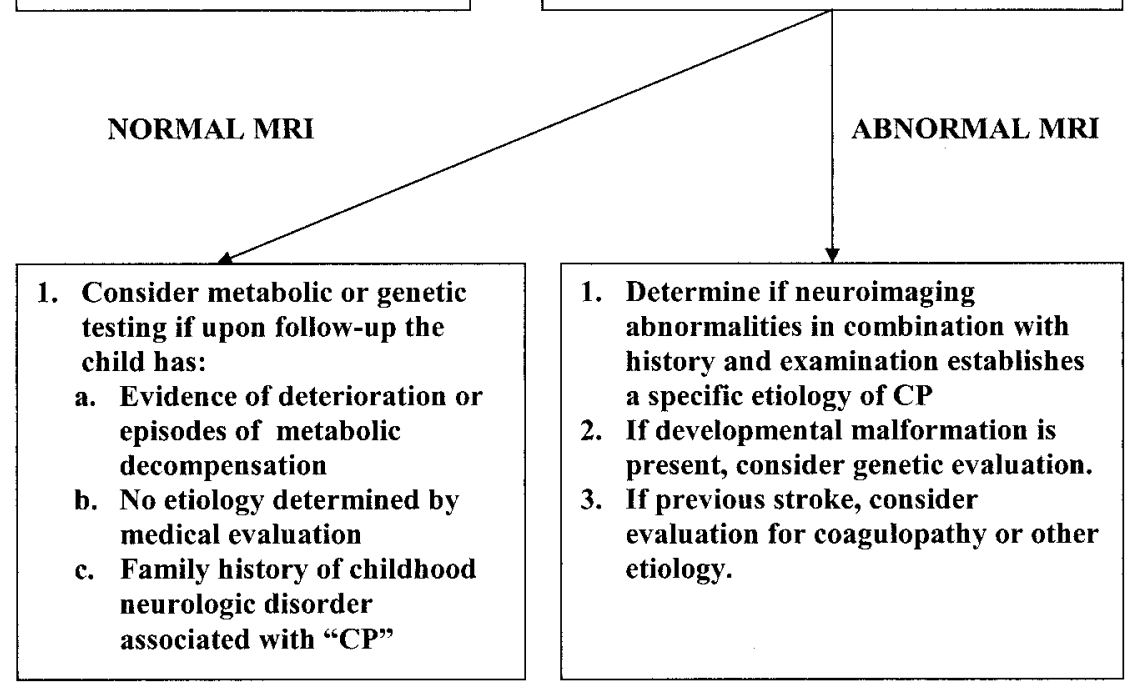

Figure. Algorithm for the evaluation of the child with cerebral palsy $(C P)$.

Screening for associated conditions (mental retardation, vision/hearing impairments, speech and language delays, oral motor dysfunction, and epilepsy) is recommended. Neuroimaging (MRI preferred to CT) is recommended for further evaluation if the etiology of the child's CP has not been previously determined. In some children, additional metabolic or genetic testing may be indicated. the history or clinical examination, metabolic and genetic testing should be considered. Because the incidence of cerebral infarction is high in children with hemiplegic CP, diagnostic testing for a coagulation disorder should be considered.

Future research. 1. Prospective studies on the etiologic yields of genetic, metabolic, and neuroimaging diagnostic tests should be undertaken in large numbers of young children with $\mathrm{CP}$ compared with control subjects. This would permit the development of specific diagnostic algorithms.

2. Large prospective cohorts of children with $\mathrm{CP}$ should be studied to identify features based on CP subtypes that can improve specific evaluation strategies and enhance etiologic yield.

3. It should be determined at what age and on what basis we can be certain that a child has CP sufficient to justify testing and at what age the yield will be optimal. Strategies of conducting testing simultaneously or sequentially need to be assessed. This should reduce unnecessary testing and provide cost-effective evaluations (i.e., a favorable balance between the cost of testing versus savings from early intervention, prevention of the birth of affected children).

4. Studies are needed to better characterize speech and language, ophthalmologic, auditory, oralmotor, nutrition, and growth deficits in children with 
CP. Investigation of the sensorimotor impairments of children with $\mathrm{CP}$ is also needed so that studies of early intervention therapies might be done to improve the overall function of children who are likely to have multiple needs.

5 . Issues related to quality of life and social support for families need further study. Included should be the benefits that medical testing confers by reducing parental concerns related to determining an etiology and by providing important information regarding prognosis, genetic counseling, and planning future educational and treatment needs.

6. Future research should also be directed to determine the underlying mechanisms causing $\mathrm{CP}$ that are associated with perinatal stroke, coagulopathies, genetic disorders, pre- and perinatal inflammatory diseases, and environmental factors.

Mission statement. The Quality Standards Subcommittee (QSS) of the AAN seeks to develop scientifically sound, clinically relevant practice parameters for the practice of neurology. Practice parameters are strategies for patient management that assist physicians in clinical decision making. A practice parameter is one or more specific recommendations based on analysis of evidence of a specific clinical problem. These might include diagnosis, symptoms, treatment, or procedure evaluation.

Disclaimer. This statement is provided as an educational service of the American Academy of Neurology and the Child Neurology Society. It is based on an assessment of current scientific and clinical information. It is not intended to include all possible proper methods of care for a particular neurologic problem or all legitimate criteria for choosing to use a specific procedure. Neither is it intended to exclude any reasonable alternative methodologies. The AAN and the CNS recognize that specific patient care decisions are the prerogative of the patient and the physician caring for the patient, based on all of the circumstances involved.

\section{Appendix 1: Members of the Quality Standards Subcommittee}

Gary Franklin, MD, MPH (Co-Chair); Gary Gronseth, MD (Co-Chair); Charles E. Argoff, MD; Stephen Ashwal, MD (ex-officio); Christopher Bever Jr., MD; Jody Corey-Bloom, MD, PhD; John D. England, MD; Jacqueline French, MD (ex-officio); Gary H. Friday, MD; Michael J. Glantz, MD; Deborah Hirtz, MD; Donald J. Iverson, MD; David J. Thurman, MD; Samuel Wiebe, MD; William J. Weiner, MD; and Catherine Zahn, MD (ex-officio).

\section{Appendix 2: Members of the Practice Committee of the Child Neurology Society}

Carmela Tardo, MD (Chair); Bruce Cohen, MD (Vice-Chair); Elias Chalhub, MD; Roy Elterman, MD; Murray Engel, MD; Bhuwan P. Garg, MD; Brian Grabert, MD; Annette Grefe, MD; Michael Goldstein, MD; David Griesemer, MD; Betty Koo, MD; Edward Kovnar, MD; Leslie Anne Morrison, MD; Colette Parker, MD; Ben Renfroe, MD; Anthony Riela, MD; Michael Shevell, MD; Shlomo Shinnar, MD; Herald Silverboard, MD; Russell Snyder, MD; Dean Timmons, MD; Greg Yim, MD; and Mary Anne Whelan, MD.

\section{References}

1. Nelson KB, Ellenberg JH. Epidemiology of cerebral palsy. Adv Neurol 1978;19:421-435.
2. Hagberg B, Hagberg G, Beckung E, et al. Changing panorama of cere bral palsy in Sweden. VIII. Prevalence and origin in the birth year period 1991-94. Acta Paediatr 2001;90:271-277.

3. Boyle CA, Yeargin-Allsopp M, Doernberg NS, et al. Prevalence of selected developmental disabilities in children 3-10 years of age: the Metropolitan Atlanta Developmental Disabilities Surveillance. MMWR $1996 ; 45: 1-14$

4. Grether JK, Cummins SK, Nelson KB. The California Cerebral Palsy Project. Paediatr Perinat Epidemiol 1992;6:339-351.

5. Ment LR, Bada HS, Barnes P, et al. Practice parameter: neuroimaging of the neonate: report of the Quality Standards Subcommittee of the American Academy of Neurology and the Practice Committee of the Child Neurology Society. Neurology 2002;58:1726-1738.

6. Wiklund LM, Uvebrant P, Flodmark O. Computed tomography as an adjunct in etiological analysis of hemiplegic cerebral palsy; II: children born at term. Neuropediatrics 1991;22:121-128.

7. Wiklund LM, Uvebrant P, Flodmark O. Computed tomography as an adjunct in etiological analysis of hemiplegic cerebral palsy. I: Children born preterm. Neuropediatrics 1991;22:50-56.

8. Miller G, Cala LA. Ataxic cerebral palsy-clinico-radiologic correlations. Neuropediatrics 1989;20:84-89.

9. Chen YH. Correlations between computerized tomography of the head and motor developmental disturbances of children with cerebral palsy. J Jpn Orthop 1981;55:85-99.

10. Kolawole TM, Patel PJ, Mahdi AH. Computed tomographic (CT) scans in cerebral palsy. Pediatr Radiol 1989;20:23-27.

11. Taudorf K, Melchior JC, Pedersen H. CT findings in spastic cerebral palsy. Clinical, aetiological and prognostic aspects. Neuropediatrics 1984;15:120-124.

12. Schouman-Claeys E, Picard A, Lalande G, et al. Contribution of computed tomography in the aetiology and prognosis of cerebral palsy in children. Br J Radiol 1989;62:248-252.

13. Cohen ME, Duffner PK. Prognostic indicators in hemiparetic cerebral palsy. Ann Neurol 1981;9:353-357.

14. Molteni B, Oleari G, Fedrizzi E, et al. Relation between CT patterns, clinical findings and etiological factors in children born at term, affected by congenital hemiparesis. Neuropediatrics 1987;18:75-80.

15. Krageloh-Mann I, Petersen D, Hagberg G, et al. Bilateral spastic cerebral palsy-MRI pathology and origin. Analysis from a representative series of 56 cases. Dev Med Child Neurol 1995;37:379-397.

16. Yin R, Reddihough D, Ditchfield M, et al. Magnetic resonance imaging findings in cerebral palsy. J Paediatr Child Health 2000;36:139-144.

17. Candy EJ, Hoon AH, Capute AJ, et al. MRI in motor delay: important adjunct to classification of cerebral palsy. Pediatr Neurol 1993;9:421-429.

18. Okumura A, Kato T, Kuno K, et al. MRI findings in patients with spastic cerebral palsy. II: Correlation with type of cerebral palsy. Dev Med Child Neurol 1997;39:369-372.

19. Cioni G, Sales B, Paolicelli PB, et al. MRI and clinical characteristics of children with hemiplegic cerebral palsy. Neuropediatrics 1999;30:249_ 255 .

20. Jaw TS, Jong YJ, Sheu RS, et al. Etiology, timing of insult, and neuropathology of cerebral palsy evaluated with magnetic resonance imaging. J Formos Med Assoc 1998;97:239-246.

21. Sugimoto T, Woo M, Nishida N, et al. When do brain abnormalities in cerebral palsy occur? An MRI study. Dev Med Child Neurol 1995;37: $285-292$.

22. Hayakawa K, Kanda T, Hashimoto $\mathrm{K}$, et al. MR imaging of spastic diplegia. The importance of corpus callosum. Acta Radiol 1996;37:830 836 .

23. Truwit CL, Barkovich AJ, Koch TK, et al. Cerebral palsy: MR findings in 40 patients. AJNR Am J Neuroradiol 1992;13:67-78.

24. Yokochi K, Aiba K, Kodama M, et al. Magnetic resonance imaging in athetotic cerebral palsied children. Acta Paediatr Scand 1991;80:818-823.

25. Haworth JC, Booth FA, Chudley AE, et al. Phenotypic variability in glutaric aciduria type I: report of fourteen cases in five Canadian Indian kindreds. J Pediatr 1991;118:52-58.

26. Kyllerman M, Skjeldal OH, Lundberg M, et al. Dystonia and dyskinesia in glutaric aciduria type I: clinical heterogeneity and therapeutic considerations. Mov Disord 1994;9:22-30.

27. Hauser SE, Peters H. Glutaric aciduria type 1: an underdiagnosed cause of encephalopathy and dystonia-dyskinesia syndrome in children. J Paediatr Child Health 1998;34:302-304.

28. Baric I, Zschocke J, Christensen E, et al. Diagnosis and management of glutaric aciduria type I. J Inherit Metab Dis 1998;21:326-340.

29. Smith WE, Millington DS, Koeberl DD, et al. Glutaric acidemia, type I, missed by newborn screening in an infant with dystonia following promethazine administration. Pediatrics 2001;107:1184-1187.

30. Hartley LM, Mrcp B, Khwaja OS, et al. Glutaric aciduria type 1 and nonaccidental head injury. Pediatrics 2001;107:174-175.

31. Mitchell G, McInnes RR. Differential diagnosis of cerebral palsy: LeschNyhan syndrome without self-mutilation. Can Med Assoc J 1984;130: 1323-1324.

32. Straussberg R, Brand N, Gadoth N. 3-Methyl glutaconic aciduria in Iraqi Jewish children may be misdiagnosed as cerebral palsy. Neuropediatrics 1998;29:54-56. 
33. Lissens W, Vreken P, Barth PG, et al. Cerebral palsy and pyruvate dehydrogenase deficiency: identification of two new mutations in the E1alpha gene. Eur J Pediatr 1999;158:853-857.

34. Prasad AN, Breen JC, Ampola MG, et al. Argininemia: a treatable genetic cause of progressive spastic diplegia simulating cerebral palsy: case reports and literature review. J Child Neurol 1997;12:301-309.

35. Willis TA, Davidson J, Gray RG, et al. Cytochrome oxidase deficiency presenting as birth asphyxia. Dev Med Child Neurol 2000;42:414-417.

36. Gibson KM, Christensen E, Jakobs C, et al. The clinical phenotype of succinic semialdehyde dehydrogenase deficiency (4-hydroxybutyric aciduria): case reports of 23 new patients. Pediatrics 1997;99:567-574.

37. Christodoulou J, Qureshi IA, McInnes RR, et al. Ornithine transcarbamylase deficiency presenting with strokelike episodes. J Pediatr 1993;122:423-425

38. Lynch JK, Nelson KB, Curry CJ, et al. Cerebrovascular disorders in children with the factor V Leiden mutation. J Child Neurol 2001;16: 735-744.

39. Gunther G, Junker R, Strater R, et al. Childhood Stroke Study Group. Symptomatic ischemic stroke in full-term neonates: role of acquired and genetic prothrombotic risk factors. Stroke 2000;31:2437-2441.

40. Mercuri E, Cowan F, Gupte G, et al. Prothrombotic disorders and abnormal neurodevelopmental outcome in infants with neonatal cerebral infarction. Pediatrics 2001;107:1400-1404.

41. Kenet G, Sadetzki S, Murad H, et al. Factor V Leiden and antiphospholipid antibodies are significant risk factors for ischemic stroke in children. Stroke 2000;31:1283-1288.

42. Golomb MR, MacGregor DL, Domi T, et al. Presumed pre- or perinata arterial ischemic stroke: risk factors and outcomes. Ann Neurol 2001; 50:163-168.

43. Harum KH, Hoon AH, Jr., Kato GJ, et al. Homozygous factor-V mutation as a genetic cause of perinatal thrombosis and cerebral palsy. Dev Med Child Neurol 1999;41:777-780.

44. Kraus FT, Acheen VI. Fetal thrombotic vasculopathy in the placenta: cerebral thrombi and infarcts, coagulopathies, and cerebral palsy. Hum Pathol 1999;30:759-769.

45. Okun MS, Jummani RR, Carney PR. Antiphospholipid-associated recurrent chorea and ballism in a child with cerebral palsy. Neurology 2000;23:62-63.

46. Thorarensen O, Ryan S, Hunter J, et al. Factor V Leiden mutation: an unrecognized cause of hemiplegic cerebral palsy, neonatal stroke, and placental thrombosis. Ann Neurol 1997;42:372-375.

47. Wallace SJ. Epilepsy in cerebral palsy. Dev Med Child Neurol 2001;43: 713-717.

48. Murphy CC, Yeargin-Allsopp M, Decoufle P, et al. Prevalence of cerebral palsy among ten-year-old children in metropolitan Atlanta, 1985 through 1987. J Pediatr 1993;123:S13-S20.

49. von Wendt L, Rantakallio P, Saukkonen AL, et al. Cerebral palsy and additional handicaps in a 1-year birth cohort from northern Finland-a prospective follow-up study to the age of 14 years. Ann Clin Res 1985; 17:156-161.

50. Zafeiriou DI, Kontopoulos EE, Tsikoulas I. Characteristics and prognosis of epilepsy in children with cerebral palsy. J Child Neurol 1999;14: $289-294$

51. Hadjipanayis A, Hadjichristodoulou C, Youroukos S. Epilepsy in patients with cerebral palsy. Dev Med Child Neurol 1997;39:659-663.

52. Al-Sulaiman A. Electroencephalographic findings in children with cerebral palsy: a study of 151 patients. Funct Neurol 2001;16:325-328.

53. Chambers HG, Weinstein CH, Mubarak SJ, et al. The effect of valproic acid on blood loss in patients with cerebral palsy. J Pediatr Orthop 1999;19:792-795.

54. Bruck I, Antoniuk SA, Spessatto A, et al. Epilepsy in children with cerebral palsy. Arq Neuropsiquiatr 2001;59:35-39.

55. Kwong KL, Wong SN, So KT. Epilepsy in children with cerebral palsy. Pediatr Neurol 1998;19:31-36.
56. Kaushik A, Agarwal RP, Sadhna. Association of cerebral palsy with epilepsy. J Ind Med Assoc 1997;95:552-554, 565

57. Senbil N, Sonel B, Aydin OF, et al. Epileptic and non-epileptic cerebra palsy: EEG and cranial imaging findings. Brain Dev 2002;24:166-169.

58. Fennell EB, Dikel TN. Cognitive and neuropsychological functioning in children with cerebral palsy. J Child Neurol 2001;16:58-63.

59. Aram DM, Eisele JA. Limits to a left hemisphere explanation for specific language impairment. J Speech Hear Res 1994;37:824-830.

60. Trauner DA, Ballantyne A, Friedland S, et al. Disorders of affective and linguistic prosody in children after early unilateral brain damage. Ann Neurol 1996;39:361-367.

61. Schenk-Rootlieb AJ, van Nieuwenhuizen O, van der Graaf Y, et al. The prevalence of cerebral visual disturbance in children with cerebral palsy. Dev Med Child Neurol 1992;34:473-480.

62. American Academy of Pediatrics Committee on Practice and Ambulatory Medicine, Section on Ophthalmology. Eye examination and vision screening in infants, children, and young adults. Pediatrics 1996;98: 153-157.

63. Hartmann EE, Dobson V, Hainline L, et al. Preschool vision screening: summary of a Task Force report on behalf of the Maternal and Child Health Bureau and the National Eye Institute Task Force on Vision Screening in the Preschool Child. Pediatrics 2000;106:1105-1116.

64. Clarke WM, Hoops HR. Predictive measures of speech proficiency in cerebral palsied speakers. J Commun Disord 1980;13:385-394.

65. Love RJ, Hagerman EL, Taimi EG. Speech performance, dysphagia and oral reflexes in cerebral palsy. J Speech Hear Disord 1980;45:59-75.

66. Uvebrant P, Carlsson G. Speech in children with cerebral palsy. Acta Paediatr 1994;83:779.

67. Falkman KW, Sandberg AD, Hjelmquist E. Preferred communication modes: prelinguistic and linguistic communication in non-speaking preschool children with cerebral palsy. Int J Lang Commun Disord 2002 37:59-68.

68. Reilly S, Skuse D, Poblete X. Prevalence of feeding problems and oral motor dysfunction in children with cerebral palsy: a community survey. J Pediatr 1996;129:877-882.

69. Sullivan PB, Lambert B, Rose M, et al. Prevalence and severity of feeding and nutritional problems in children with neurological impair ment: Oxford Feeding Study. Dev Med Child Neurol 2000;42:674-680.

70. Waterman ET, Koltai PJ, Downey JC, et al. Swallowing disorders in a population of children with cerebral palsy. Int J Pediatr Otorhinolaryngol 1992;24:63-71.

71. Blasco PA, Allaire $\mathrm{JH}$, participants of the Consortium on Drooling. Drooling in the developmentally disabled: management practices and recommendations. Dev Med Child Neurol 1992;34:849-862.

72. Stallings VA, Charney EB, Davies JC, et al Nutrition-related growth failure of children with quadriplegic cerebral palsy. Dev Med Child Neurol 1993;35:126-138.

73. Blasco PA, Stansbury JC. Glycopyrrolate treatment of chronic drooling. Arch Pediatr Adolesc Med 1996;150:932-935

74. Pope JE, Curzon ME. The dental status of cerebral palsied children Pediatr Dentistry 1991;13:156-162.

75. Shaw BNJ. The respiratory consequences of neurological deficit. In: Sullivan PB, Rosenbloom L, eds. Feeding the disabled child. Clinics in developmental medicine no. 140. New York: Cambridge University Press, 1996;40-46.

76. Van Naarden K, Decoufle P, Caldwell K. Prevalence and characteristics of children with serious hearing impairment in metropolitan Atlanta, 1991-1993. Pediatrics 1999;103:570-575.

77. Joint Committee on Infant Hearing, American Academy of Audiology, American Academy of Pediatrics, American Speech-Language-Hearing Association, and Directors of Speech and Hearing Programs in State Health and Welfare Agencies. Position statement: principles and guidelines for early hearing detection and intervention programs. Pediatrics $2000 ; 106: 798-817$ 


\section{Neurology}

Practice Parameter: Diagnostic assessment of the child with cerebral palsy: Report of the Quality Standards Subcommittee of the American Academy of Neurology and the Practice Committee of the Child Neurology Society

S. Ashwal, B. S. Russman, P. A. Blasco, et al. Neurology 2004;62;851-863

DOI 10.1212/01.WNL.0000117981.35364.1B

This information is current as of March 22, 2004

\section{Updated Information \& Services}

References

Citations

Subspecialty Collections

Permissions \& Licensing

Reprints including high resolution figures, can be found at: http://n.neurology.org/content/62/6/851.full

This article cites 75 articles, 14 of which you can access for free at: http://n.neurology.org/content/62/6/851.full\#ref-list-1

This article has been cited by 18 HighWire-hosted articles: http://n.neurology.org/content/62/6/851.full\#\#otherarticles

This article, along with others on similar topics, appears in the following collection(s):

All Clinical Neurology

http://n.neurology.org/cgi/collection/all_clinical_neurology

All Pediatric

http://n.neurology.org/cgi/collection/all_pediatric

Childhood stroke

http://n.neurology.org/cgi/collection/childhood_stroke

Developmental disorders

http://n.neurology.org/cgi/collection/developmental_disorders

Information about reproducing this article in parts (figures,tables) or in its entirety can be found online at:

http://www.neurology.org/about/about_the_journal\#permissions

Information about ordering reprints can be found online:

http://n.neurology.org/subscribers/advertise

Neurology ${ }^{\circledR}$ is the official journal of the American Academy of Neurology. Published continuously since 1951, it is now a weekly with 48 issues per year. Copyright . All rights reserved. Print ISSN: 0028-3878. Online ISSN: 1526-632X.

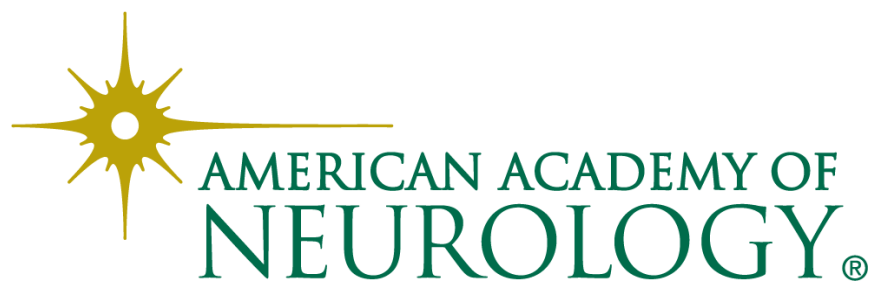

